\title{
STUDY ON SAFETY TECHNOLOGY SCHEME OF THE UNMANNED HELICOPTER
}

\author{
Lin Zhaorong $^{\text {a }}$, Zhang Weiwei ${ }^{\mathrm{a}, *}$, Chen Shiying ${ }^{\mathrm{b}}$, Liu Tao ${ }^{\mathrm{a}}$, Yao Yigang ${ }^{\mathrm{a}}$ \\ ${ }^{a}$ Beijing Institute of Space Mechanics \& Electricity, Zhongguancun East road 99, Haidian District, Beijing, China - \\ Linzhaorong1234@126.com,wwliuz@gmail.com,jz92_1t@163.com,yaoyigang2009@126.com \\ ${ }^{\mathrm{b}}$ Air Sounding and Technical Support Center of Inner Mongolia, Huhout,010051 - chenshiying260@163.com
}

KEY WORDS: Unmanned helicopter, Fault analysis, Safety design, Safety parachute scheme

\begin{abstract}
:
Nowadays the unmanned helicopter is widely used for its' unique strongpoint, however, the high failure rate of unmanned helicopter seriously limits its further application and development. For solving the above problems, in this paper, the reasons for the high failure rate of unmanned helicopter is analyzed and the corresponding solution schemes are proposed. The main problem of the failure cause of the unmanned helicopter is the aircraft engine fault, and the failure cause of the unmanned helicopter is analyzed particularly. In order to improving the safety performance of unmanned helicopter system, the scheme of adding the safety parachute system to the unmanned helicopter system is proposed and introduced. These schemes provide the safety redundancy of the unmanned helicopter system and lay on basis for the unmanned helicopter applying into residential areas.
\end{abstract}

\section{INTRODUCTION}

Unmanned helicopter has been used in many fields about lowaltitude resource with more and more attentions ${ }^{[1]}$ due to the characteristics of small size, hovering in the air and low terrain requirement for the landing and taking off ${ }^{[2][3]}$. Especially employing unmanned helicopter for the building mapping in photogrammetry can improve the mapping accuracy, ensure the security of staff and acquire high work efficiency. The safety of the unmanned helicopter is a challenge for the applied into the photogrammetry. There are two main reasons for the high failure rate of the unmanned helicopter ${ }^{[4]}$, which has seriously limited its widely application, especially in areas with dense population. Firstly, it is mainly due to its own vulnerabilities and characteristics in the structure and the flight control. There are so many rotating parts, loads and propeller will be loaded into the unmanned helicopter, so it is hard to automatically sense the alternating load and avoid the fatigue failure for the vibration of the helicopter. Secondly, it is due to the bad and dangerous circumstance when the unmanned helicopter is in flight, such as the mountain areas, the thick forest, the city and the bad weather condition.

The rest of this paper is organized as follows. In the next section, we present the main causes of unmanned helicopter fault in detail and issue some feasible solution schemes. In the third section, the safety parachute scheme is proposed and the analysis result of the safety parachute is shown. We conclude the paper in the last section.

\section{FAULT ANALYSIS OF THE UNMANNED HELICOPTER}

When the unmanned helicopter is in mission-performing, it will have a long distance flight out sight of the operator's view. The flight control system plays a pilot role with high requirements of safety. In the initial stage, some security and fault-tolerance design strategies will integrated into the flight control system of the unmanned helicopter. By adopting these strategies, the unmanned helicopter is expected to avoid the flight accident and guarantee the safety of the unmanned helicopter platform in case of the equipment failure event. In order to analyze the fault of the unmanned helicopter, it is necessary to understand the flight control system, as is an important and core part of the unmanned helicopter. The structure of the flight control system is shown in fig. 1 .

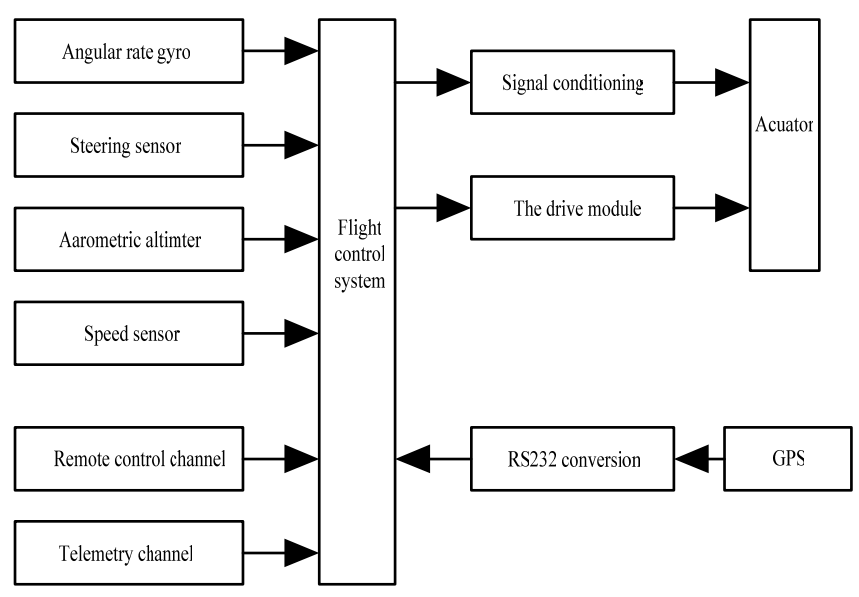

Figure 1. The flight control system of the unmanned helicopter

The main reasons of the unmanned helicopter fault ${ }^{[5]-[9]}$ are the failure of the communication link, system hardware fault, the motor fault and the failure of the propeller. The system hardware fault mainly include the failure of the actuator, sensor

\footnotetext{
* Corresponding author. This is useful to know for communication with the appropriate person in cases with more than one author.
} 
failure, the flight control computer fault, the interruption of signal driving circuit, power supply fluctuations disorder and even failure in the air. The probability of the system hard ware fault is not high for the complete product of the unmanned helicopter. It can be reduced by means of high reliability hardware and correct setting according to specification of the installation. The propeller fault mainly makes up of the blade flick, the ground objects cut by the blade, tail propeller speed reducer failure or tail propeller blade tip weighting off, control rod fracture, needle on the failure and so on. In order to ensure the system safety, the propeller of the helicopter can adopt a new type of high performance composite materials such as carbon fibre to tackle the vibration of the system. Communication link failure is mainly including radio channel interrupt, signal interference etc. The improvement for the communication link failure is to install the high performance GPS system in unmanned helicopter with autopilot, which helps the flight control computer system to record the complete flight path including the position and time data and adjust the state according to the records. The helicopter can run in the automatic adjustment mode and keep hovering. After the automatic route planning function restarted, the unmanned helicopter can fly back along the foregoing route. Due to the fuel depletion, unexpectedly halt or engine on fire, the unmanned helicopter will run out of power and lead to the emergence of great danger. For this fault, we will propose a safety parachute scheme to improve the safety of whole system and avoid damage to the ground personnel.

\section{THE UNMANNED HELICOPTER SAFETY PARACHUTE SYSTEM}

If the unmanned helicopter bumps into the engine fault, this is very dangerous. In order to ensure the safety of unmanned helicopter system, safety parachute system is increased for unmanned helicopter system ${ }^{[10]}$. Under the normal operating conditions, the unmanned helicopter can adjust their attitude and propeller speed to achieve a safe landing. When the unmanned helicopter encounters out of control and some other emergency situations, the safety parachute system is employed to ensure the helicopter slowing down and reduce the shock of impact when hitting the ground. It also creates the favourable conditions for the analysis of fault in order to rescue the unmanned helicopter. On the other hand, it can provide more evacuation time for the ground people to escape, and it raise the possibility of the whole unmanned helicopter working in residential areas.

The speed detecting device is included in the safe parachute system. When the engine works abnormally, abnormal signals will be emitted after the $10 \mathrm{~ms}$ ' delay and the helicopter is deemed to being in trouble. Then parachute will be opened and the parachute process is started. First of all, the propeller spindle brakes to deceleration. Then, the parachute is ejected, and the warning device is opened to making the harshness noise at the same time. The schematics of the installation, location and the call-back process of unmanned helicopter parachute system are shown in fig. 2.

The safe parachute system needs a high parachute resistance coefficient for the limited space, so the square umbrella is employed as resistance coefficient of the square umbrella is greater than that of the flat circular parachute. When the rate of decline of the unmanned helicopter is less than $7 \mathrm{~m} / \mathrm{s}$, the resistance coefficient of the parachute will increase significantly. The disadvantages of the square parachute are the uneven stress, the irrational structure, four inward contraction corners of the bottom and easy to cause umbrella rope whipping the canopy. However, the umbrella load is not heavy, so the influence of uneven stress and structural layout unreasonable shortcoming is not so prominent. After considering the advantages and disadvantages of square umbrella, the square umbrella is chosen.

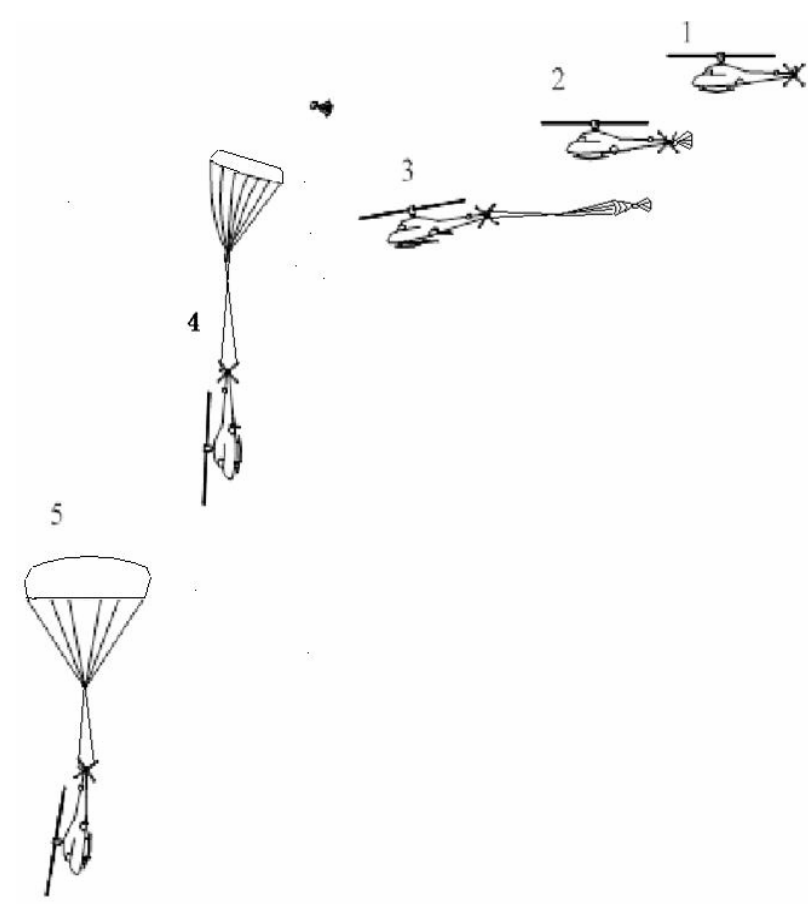

The call-back process:

1. Propeller braking

2. The umbrella canopy is wiped off, and the guide parachute is pulled.

3. The guide parachute pull out the main umbrella.

4. The main umbrella is inflated, and the gesture of the unmanned helicopter is changed.

5. The main umbrella is fully unfolded, the whole helicopter is uniform descent.

Figure 2. The installation, location and the call-back

process of unmanned helicopter parachute system

The weight of the unmanned helicopter is $40 \mathrm{~kg}$, the helicopter level flight speed is $35 \mathrm{~m} / \mathrm{s}$, then the resistance area of the parachute is 12 square meters, and the touchdown speed of the unmanned helicopter is reduced to $7-8 \mathrm{~m} / \mathrm{s}$. The parachute weighs is about $2.5 \mathrm{~kg}$, parachute cabin volume is not less than $3 \mathrm{~L}$. If the call-back height of the unmanned helicopter is $300 \mathrm{~m}$, it will take $41 \mathrm{~s}$ to touchdown. The time of the average human hedging reaction time is $2 \mathrm{~S}$, so the human have sufficient time to escape.

The ejection will use the mature catapult products on the market. Its weight is about $0.4 \mathrm{~kg}$, the outer circle size is $\Phi 22 \mathrm{~mm}$, and it can shoot off the object of $2.5 \mathrm{~kg}$ to $20 \mathrm{~m} / \mathrm{s}$. Using this device can ensure that object of $1.5 \mathrm{~kg}$ will be ejected to speed of $15 \mathrm{~m} / \mathrm{s}$, then the parachute will be opened smoothly in case of engine emergency. The layout of the unmanned helicopter ejection is shown in figure 3.

Circuit principle diagram of emergency parachute system is shown in Figure 4. The temporary emergency call-back can be started automatically by manual remote start or typical fault indicator, while the call-back start program is used to perform the call-back condition judgment. If it has the failure to start the call-back parachute system, the program will automatically 
delay 10 s to determine whether it is the real fault to start the call-back. If the fault signal continues, it will start the call-back parachute. If the fault signal is released, the call-back parachute will be closed. If the remote control system sends the call-back start command, the safe parachute will directly start the callback program. In order to ensure the reliability of emergency call-back system, the independent power will be supplied. In order to minimize the weight and space of the power, the battery capacity should be determined according to the actual demand. Meanwhile the battery's test and replacement convenience should be considered in the design.

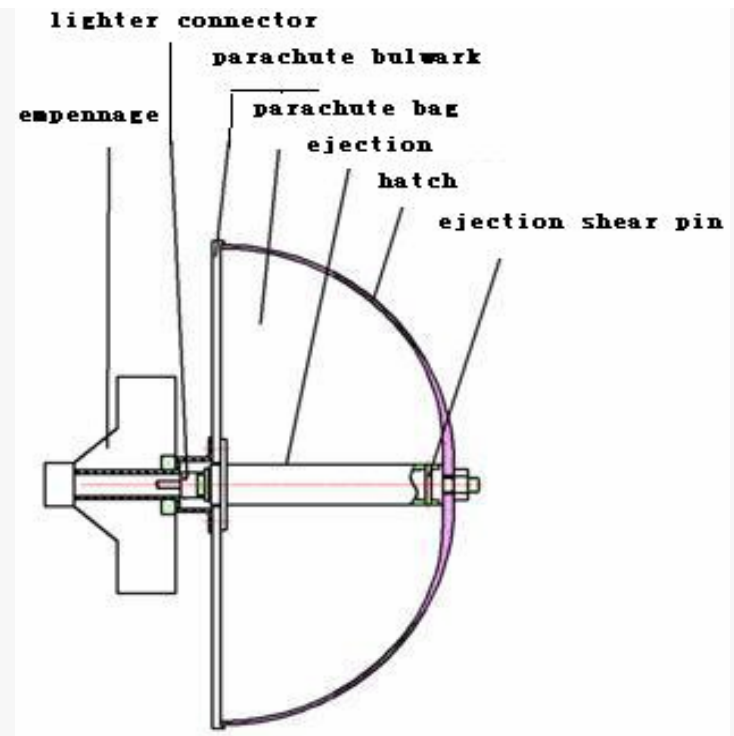

Figure 3. The layout of the unmanned helicopter ejection

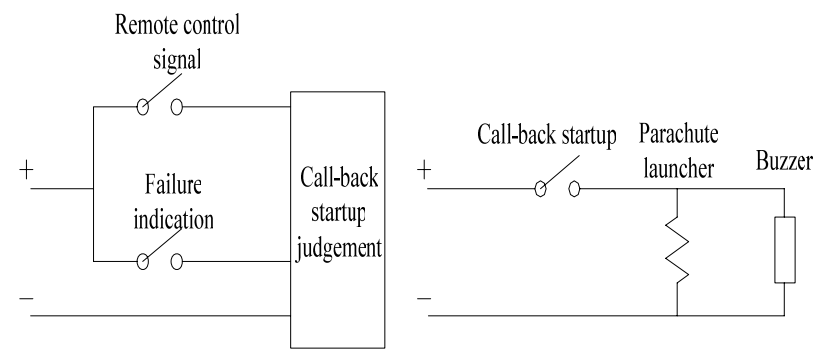

Figure 4. The Circuit principle diagram of emergency parachute system

According to the initial conditions of the safe parachute system, the ground elevation is assumed approximately zero, and the unmanned helicopter be regarded as an approximate particle. When the opening umbrella point's relative height is 300 meters, the unmanned helicopter's speed curve after opening the umbrella is shown in Figure 5. The relationship between the opening umbrella height and time is shown in figure 6 .

This scheme of the safe parachute system provides a theoretical basis for the system security system of unmanned helicopter, and it makes it possible for the unmanned helicopter to be widely used in various fields, especially, in residential areas.

\section{THE CONCLUSION}

This paper firstly introduces the reasons that the application of the unmanned helicopter is limited in photogrammetry and it can't be widely used in residential areas. The main cause of unmanned helicopter fault is also analyzed. According to different reasons, the security strategy is presented. The engine failure of the unmanned helicopter is the main fault, when the unmanned helicopter encounters the engine failure, it will be fatal to the whole unmanned helicopter. Therefore, the unmanned helicopter safety parachute system is proposed and is used to ensure the unmanned helicopter system's safety.

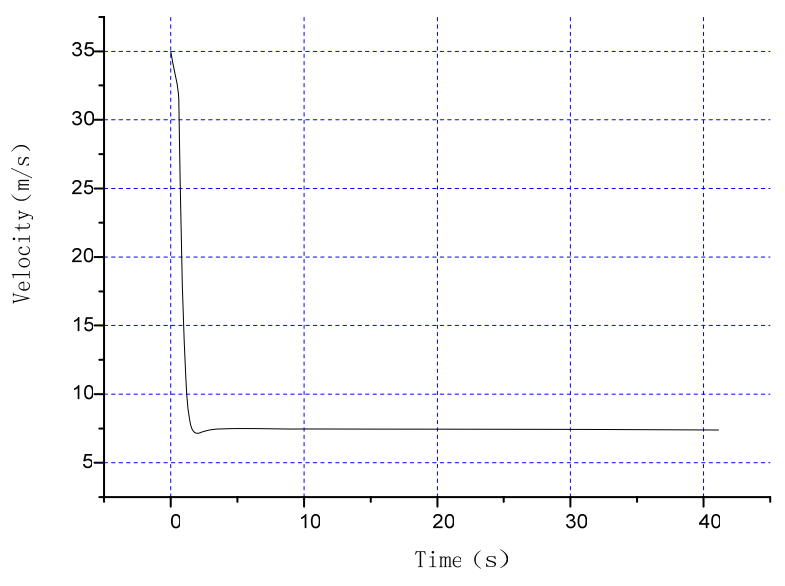

Figure 5. The unmanned helicopter's speed curve after opening the umbrella

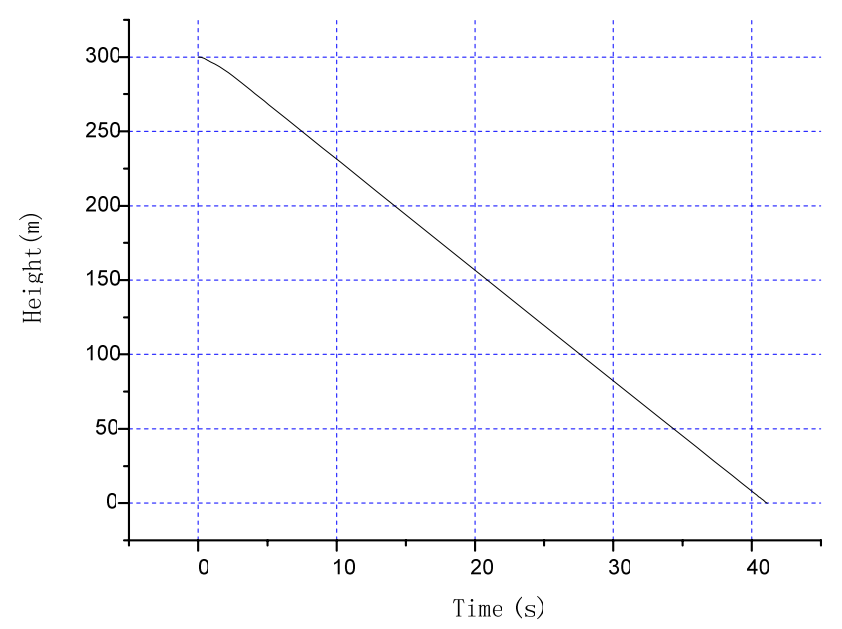

Figure 6. The relationship between the opening umbrella height

$$
\text { and time }
$$

According to the results of the analysis and calculation of the safe parachute scheme in unmanned helicopter system, this callback and alarming system can slow down the unmanned helicopter system's falling velocity. Meanwhile the damage degree of the whole equipment system can be reduced, and it also create the advantaged conditions for the analysis of fault in order to rescue the unmanned helicopter; on the other hand, this safety parachute system can emit the buzzer alarm when the system works, and it can ensure the ground people to get more adequate evacuation time to escape, and this provides the possibility of the whole unmanned helicopter working in residential areas. 
The novelty security strategic scheme is proposed in this paper, and this scheme can increases the safety redundancy of the unmanned helicopter system, and this work lays a basis for the unmanned helicopter system's further development.

\section{LITERATURE}

[1] Wang Feng, Wu Yundong, 2010.Research and application of UAS Borne remote sensing. Remote Sensing Information, pp.114-118.

[2] Lin Han, Lin Chaohui, Tang Mingwen, Dai Lihao, 2011. Application of unmanned helicopter patrol to power transmission Line. East China Electric Power, 39(10),pp.16571660 .

[3] Zhu Qinghua, Sun Qiang, 2005. Advanced technologies for helicopter safety and survivability. Aeronautical Science and Techology, 5, pp.3-6.

[4] Wang Xianlun, 2011. Discussion on security issues of UAV application. Geomatics \& Spatial Information Technology, 34(1), pp.87-91.

[5] Sun Chuanwei, Gu Donglei,2005. Investigation of the Safety Policy of the Flight control system design for the unmanned helicopter. The Second UAV Conference of the China Aviation Institute, pp.1-5.

[6] Li Yan, Chen Hai, Zhang Qingjiang, Zhao Kairui, 2011. Assessment method of health condition for UAV systems. Systems Engineering and Electronics, 33(3),pp. 562-567.

[7] Li Yongke, Chen Zili, Tian Qingmin, 2003. Research of fault online detect of UAV engine start and pull up circuit. Journal of Test and Measurement Technology, 17(3), pp.41-44.

[8] Jia Caijuan, Zhu Xiaoping, Zhou Zhou, 2005. The study and simulation of sensor fault diagnosis for an UAV control system. Computer Simulation,22(11),pp.53-55.

[9] Chen Wei, Luo Hua,2009. The multisensory data fusion technology and the UAV PHM system. Aeronautical Science and Technology, General review, pp.6-16.

[10] Deng Haifei, Lu Yanmei, Wang Jialin, Wang Gefang, Chen Wei,2012. FMECA for parachuted recovery system of a type UAV. Equipment Environment Engineering, 9(3),pp.90-98. 